\title{
Characterization of Chemically Amplified Resists with " Acid Amplifier" for 193 nm Lithography
}

\author{
Takeshi Ohfuji, Makoto Takahashi, Masaru Sasago, \\ Soh Noguchi ${ }^{\ddagger}$ and Kunihiro Ichimura ${ }^{\ddagger}$ \\ ASET \\ 292 Yoshida, Totsuka, Yokohama 244, Japan, \\ ${ }^{\ddagger}$ Tokyo Institute of Technology \\ 4259 Nagatsuta, Midori-ku, Yokohama 226, Japan
}

\begin{abstract}
We analyzed the characteristics of acid amplified positive resists designed for $193 \mathrm{~nm}$ lithography. The acid amplified resists are composed of an acid generator, a partially protected alicyclic polymers and an acid amplifier which is designed to produce acid during post-exposure baking. We first investigated the lithographic performance of acid amplified resists. Then we have simulated acid amplification reactions and calculated process window improvement. The simulation analysis clarified that acid amplification slightly contributes to increasing the process margin.
\end{abstract}

Keywords: $193 \mathrm{~nm}$, ArF, chemically amplification, acid amplification, resist

\section{INTRODUCTION}

Lithography at a wavelength of $193 \mathrm{~nm}$ is expected to be the most promising lithography method below the $0.2 \mu \mathrm{m}$ design rule. Many transparent polymer materials have been proposed for exposure at a wavelength of $193 \mathrm{~nm}$. [1-5] However, two problems still remain to be solved: sensitivity and process window. Optics designers require a resist sensitivity of $5 \mathrm{~mJ} / \mathrm{cm}^{2}$ due to the problem of glass compaction. This sensitivity is much higher than that achieved in a resist exposed at $248 \mathrm{~nm}$. Therefore, a more effective reaction system is required for the $193 \mathrm{~nm}$ resist material. The process window decrease is a more difficult problem. Figure 1 shows simulated process window dependence on wavelengths. The process window criteria is $\pm 10 \%$ cd change and 83 degree side-wall angles. We assumed a PFI26 equivalent resist parameter for all wavelength. The design rule was calculated from the same $K_{1}$ factor $(=0.6)$. Figure 1 clearly indicates that the process window decreases as the wavelength becomes shorter. The process window at $193 \mathrm{~nm}$ has an area one fourth of that of obtained under $365 \mathrm{~nm}$ lithography.

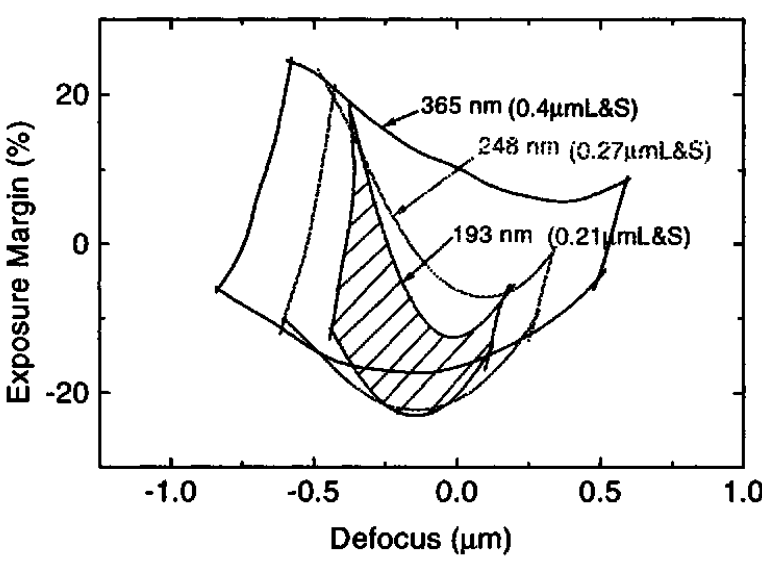

Figure 1. Simulated process window dependence on exposure wavelength.

Figure 2 shows the effectiveness of the resolution enhancement techniques. The techniques combine the use of a half-tone mask and annular illumination, which is one of the more promising illumination techniques. Figure 2 shows that the depth of focus is improved quite a bit, but the exposure margin can not be improved with these techniques. This process window decrease is the most difficult problem to solve in $193 \mathrm{~nm}$ lithography. 


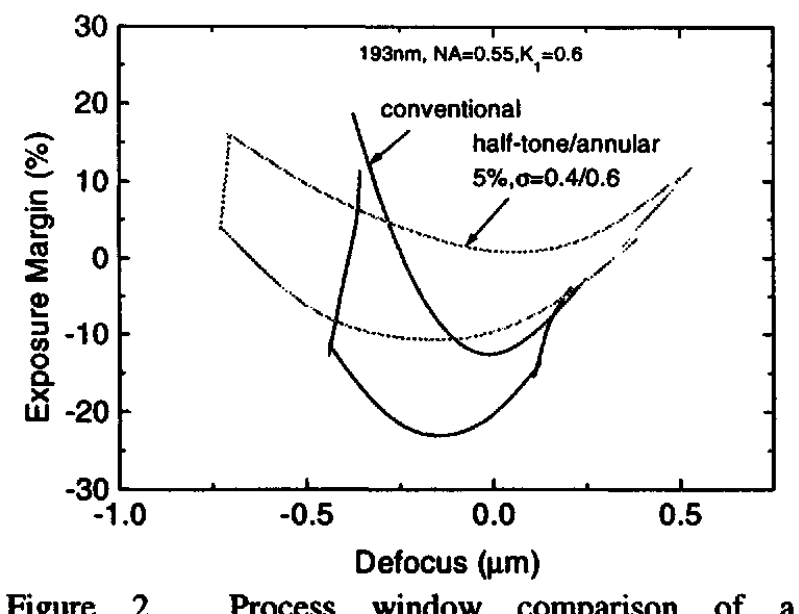

Figure 2. Process window comparison of a conventional mask and half-tone + annular illumination.

We propose acid amplification as a mechanism to solve this problem. Acid amplification is different from chemical amplification. The acid amplified resist has a two acid catalyzed reaction, whereas an usual chemically amplified resist has one catalyzed reaction. It was originally proposed by Ichimura in 1995 for improving resist sensitivity.[6-12] Ichimura et al. applied it to resist at $313 \mathrm{~nm}$ and showed that it improved resist sensitivity by one order of magnitude. In this paper, we clarify the effectiveness of introducing acid amplification mechanism into a $193 \mathrm{~nm}$ resist.

\section{EXPERIMENTAL}

\subsection{Materials}

The polymer used in this experiment is methacrylate a terpolymer with alicyclic groups as shown in Fig. 3. We used $\alpha$-methylolbenzointosylate $(\alpha-\mathrm{MBT})$ as a photo-acid generator (1 wt\%: Fig. 4) and the 1,2-diol monotosylate derivatives as an acid amplifier (2-5 wt\%: Fig. 5). [13] In addition to this resist system, we also used an ArF resist sample composed of a methacrylate polymer with alicyclic groups.

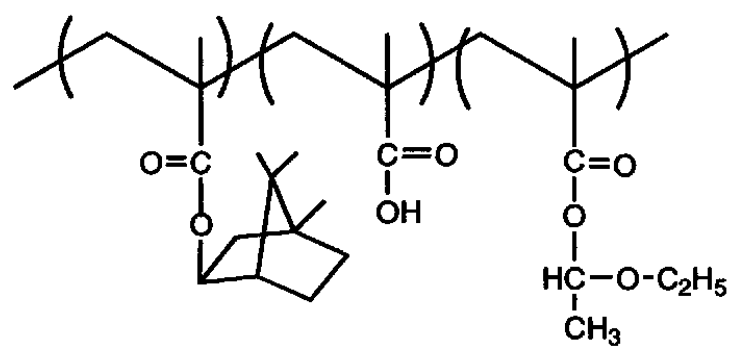

Figure 3. Polymer structure (IBMA $3-\mathrm{MAA}_{2}-\mathrm{EEMA}_{5}$ ).

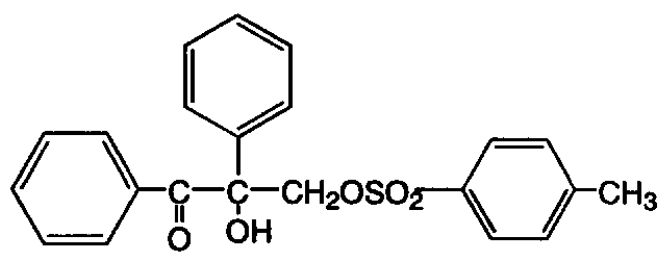

Figure 4. Photo-acid generator structure $\alpha$ methylolbenzointosylate (MBT).

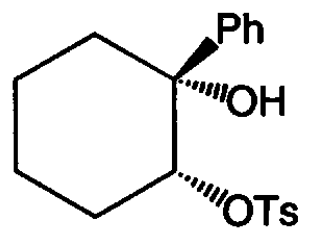

Figure 5. Acid amplifier (1,2-DiolMonotosylate)

\subsection{Process}

The resists were spin-coated onto a $\mathrm{Si}$ substrate and baked at $100{ }^{\circ} \mathrm{C}$ for $60 \mathrm{~s}$. The standard resist thickness was $0.5 \mu \mathrm{m}$. The wafers were then exposed with a Nikon ArF exposure system (NA=0.55), post-exposure baked (PEB), then developed in a tetramethylammonium hydroxide (TMAH) solution. The concentration of TMAH in the developer was $0.119 \%$ for IBMA $_{3}-\mathrm{MAA}_{2}-\mathrm{ETEMA}_{5}$ and $2.38 \%$ for the $\mathrm{ArF}$ test resist sample. These conditions are listed in Table 1.

Table 1. Materials and standard process conditions

\begin{tabular}{|c|c|c|}
\hline PROCESS & \multicolumn{2}{|c|}{ CONDITONS } \\
\hline polymer & $\begin{array}{l}\mathrm{IBMA}_{3}-\mathrm{MAA}_{2}- \\
\text { ETEMA }_{5}\end{array}$ & ArF resist \\
\hline PAG & $\alpha-\mathrm{MBTsOH}(1 \mathrm{wt} \%)$ & \\
\hline $\begin{array}{c}\text { acid } \\
\text { amplifier }\end{array}$ & \multicolumn{2}{|c|}{ DMTsOH (0-5wt\%) } \\
\hline pre bake & $90^{\circ} \mathrm{C} / 60 \mathrm{~s}$ & $100^{\circ} \mathrm{C}, 60 \mathrm{~s}$ \\
\hline exposure & \multicolumn{2}{|c|}{$193 \mathrm{~nm}, \mathrm{NA}=0.55$ (Nikon) } \\
\hline PEB & $100^{\circ} \mathrm{C}, 60 \mathrm{~s}$ & $100^{\circ} \mathrm{C}, 60 \mathrm{~s}$ \\
\hline developer & ТМАН $0.119 \%$ & TMAH $2.38 \%$ \\
\hline
\end{tabular}

Figure 6 shows the expected reaction in an acid amplified resist system. A photo-acid generator (PAG) produces acid from the exposure. The generated acid then decomposes the acid amplifier and produces acid during the PEB process. The acid generated from the acid 
amplifier also works to decompose the acid amplifier again. Thus this reaction has positive feedback. The produced acid also contributes to the deprotection reaction of the polymer at the same

time.

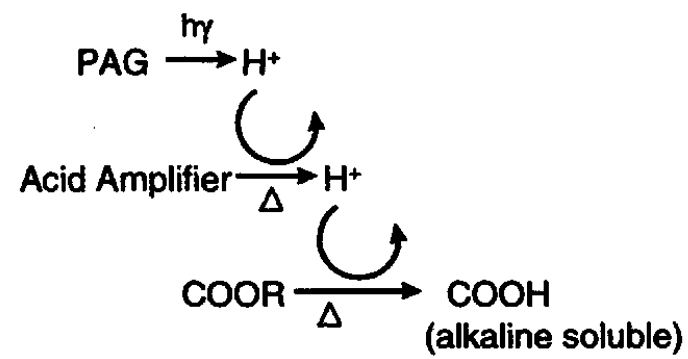

Figure 6. Expected reaction scheme of acid amplified resist system.

\section{RESULTS}

\subsection{Sensitivity}

Figure 7 shows the resist sensitivity curves after the development. The dose required to dissolve all of the film $\left(\equiv \mathrm{E}_{0}\right)$ is about $10 \mathrm{~mJ} / \mathrm{cm}^{2}$ for the resist without an acid amplifier. The $\mathrm{E}_{0}$ for the resist with an acid amplifier of $2 \%$ improved to $7 \mathrm{~mJ} / \mathrm{cm}^{2}$. However, the incorporation of an acid amplifier of $5 \%$ has the same $E_{0}$, since the slope of the sensitivity curve decreased. This reduced slope is caused by the absorbance increase, since the acid amplifier had high absorbance at $193 \mathrm{~nm}$. Although incorporating a larger amount of acid amplifier generally results in higher sensitivity, the amount of acid amplifier that can be incorporated is limited by its absorbance. Therefore, a more transparent acid amplifier is required for $193 \mathrm{~nm}$ resists.

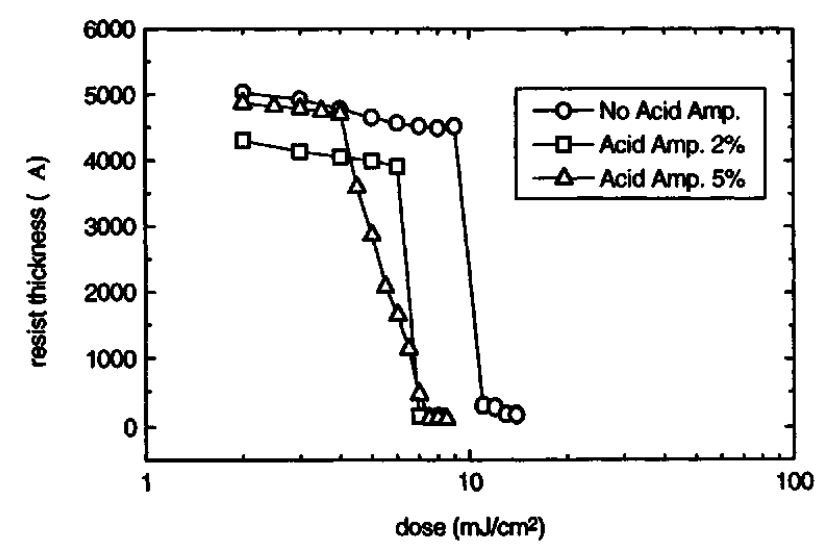

Figure 7. Sensitivity curves for an acid amplified resist system.

(IBMA $_{3}$-MAA -ETEMA $_{2}: 0.5 \mu \mathrm{m}$ thickness)
To decrease the total film absorbance, we tried using thinner resists. Figure 8 shows the sensitivity curves with a resist thickness of $0.3 \mu \mathrm{m}$. The sensitivity of the 5\% acid amplifier loading clearly improved.

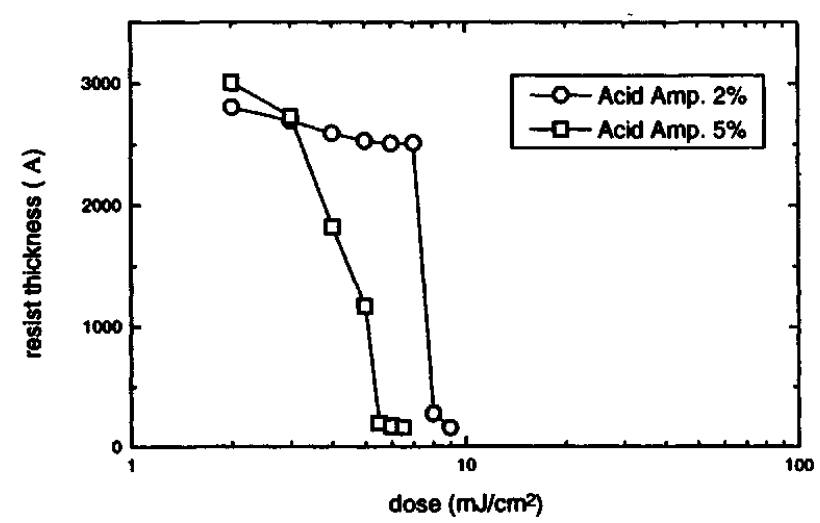

Figure 8. Sensitivity curves of thinner resists. (IBMA $A_{3}-\mathrm{MAA}_{2}$-ETEMA $\mathrm{A}_{5}: 0.3 \mu \mathrm{m}$ thickness)

\subsection{Resolution}

Figure 11 shows a cross sectional view of the resist patterns. Incorporation of $2 \%$ of the acid amplifier clearly improves the resolution characteristics. It resolves down to $0.15 \mu \mathrm{m} L \& S$, whereas the reference resist can resolve to only $0.18 \mu \mathrm{m}$ L\&S. However, the resist with the acid amplifier of $5 \%$ resulted in poor resolution and tapered profiles. This is caused by the absorbance increase caused by the acid amplifier. Therefore, a transparent acid amplifier will be required for further improvement.

Figure 12 shows another example of the patterning characteristics of the acid amplified resist. The resist without the acid amplifier tends to have a clear $t$-shape, since the polymer is hydrohobic due to alicyclic groups, and the resist becomes sensitive to contaminants. Acid amplified resists did not show the t-top profile, instead they exhibited a rounded top surface in contrast to normal chemically amplified resists. Consequently, the acid amplified resist showed higher resolution characteristics. Another possible reason for high resolution is that if the order of reaction of the acid amplification is bigger than 1, the acid amplificatin mechanism itself would essentially enhance the resolution. The tapered profiles of the acid amplification resists are a result of the higher absorbance caused by the acid amplifier. A more transparent acid amplifier will be required in the future for adequate acid amplifier loading without degradation of the pattern profiles. 


\begin{tabular}{|c|c|c|c|}
\hline & \multicolumn{3}{|c|}{ Acid amplifier contents } \\
\hline & No & $2 w t \%$ & $5 w t \%$ \\
\hline $0.14 \mu \mathrm{m} L \& S$ & & & \\
\hline $0.15 \mu \mathrm{m}$ L\&S & & & \\
\hline $0.16 \mu \mathrm{m} L \& S$ & & & \\
\hline $0.18 \mu \mathrm{m} L \& S$ & & & 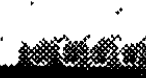 \\
\hline $0.2 \mu \mathrm{m} L \& S$ & & & \\
\hline
\end{tabular}

Figure 11. Resist pattern profiles of the acid amplified resist.

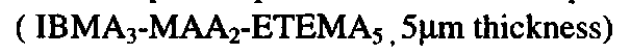

\begin{tabular}{|c|c|c|}
\hline & \multicolumn{2}{|c|}{ Acid amplifier contents } \\
\hline & No & $2 w t \%$ \\
\hline $0.16 \mu \mathrm{m}$ L\&S & & What \\
\hline $0.18 \mu \mathrm{m}$ L\&S & & HU \\
\hline $0.2 \mu \mathrm{m} \mathrm{L \& S}$ & & $A 111$ \\
\hline $0.25 \mu \mathrm{m}$ L\&S & & (n) \\
\hline $0.3 \mu \mathrm{m}$ L\&S & & $=8$ \\
\hline
\end{tabular}

Figure 12. Resist pattern profiles of the acid amplified resist.

( ArF test sample, $5 \mu \mathrm{m}$ thickness)

We found that incorporating an acid amplifier has other subsidiary effects besides improving sensitivity. One of these effects is the advantage of improved adhesion. Acid amplified resists show higher adhesion. The other is dissolution smoothness which causes no residue after the development.

\section{DISCUSSION}

We simulated an acid amplification reaction and will discuss the potential of acid amplified resists.

\subsection{Reaction analysis}

The reactions for the acid generation and acid amplification processes are described as follows, 


$$
P A G \stackrel{h \gamma}{\longrightarrow} H^{+}{ }_{P A G}+P_{P A G}
$$

$$
A A \stackrel{\Delta, H^{+}}{\longrightarrow} H^{+}{ }_{A A}+P_{A A}
$$

PAG is the Photo Acid Generator, $\mathrm{H}_{\text {PAG }}^{+}$is the acid generated from PAG, $P_{\mathrm{PAG}}$ represents products from PAG, AA is the Acid Amplifier, $\mathrm{H}^{+}{ }_{\mathrm{AA}}$ is the acid generated from the acid amplifier , and $\mathrm{P}_{\mathrm{AA}}$ represents the products from the acid amplifier. In the acid amplification reaction, acid generation reaction can be expressed as follows, [13]

$$
\Delta[A A]=-K_{A A}[A A]\left[H^{+}\right]^{m} \Delta t^{\prime}
$$

Here $[\mathrm{AA}]$ is the acid amplifier concentration normalized to the initial acid amplifier concentration, $\mathrm{K}_{\mathrm{AA}}$ is the reaction constant, $\left[\mathrm{H}^{+}\right]$is the normalized acid concentration, $m$ is reaction order, and $t^{\prime}$ is PEB time. The amount of acid is the sum of the acid from the PAG and the acid from an acid amplifier, then

$$
\left[\mathrm{H}^{+}\right]_{T O T A L}=r\left[H^{+}\right]_{P A G}+\left[H^{+}\right]_{A A}
$$

Here $r$ is PAG concentration relative to the acid amplifier concentration. Moreover,

$$
\left[H^{+}\right]_{A A}=1-[A A]
$$

substituting this into equation (2), we get

$$
\left[\mathrm{H}^{+}\right]_{\text {TOTAL }}=r\left[\mathrm{H}^{+}\right]_{P A G}+1-[\mathrm{AA}]
$$

Next, we will solve the given equations and analyze the acid amplification reaction quantitatively.

(i) when $\mathrm{m}=1$.

We first analyze the most simple case, when $m=1$. From equation (1) to (3),

$$
\begin{aligned}
\Delta[A A] & =-K_{A A}[A A]\left(r\left[H^{+}\right]_{P A G}+1-[A A]\right) \Delta t^{\prime} \\
& =-K_{A A}\left(-[A A]^{2}+\left(r\left[H^{+}\right]_{P A G}+1\right)[A A]\right] \Delta t^{\prime}
\end{aligned}
$$

By rearranging these equations, we get

$$
\frac{\Delta[A A]}{\left(r\left[H^{+}\right]_{P A G}+1\right)[A A]-[A A]^{2}}=-K_{A A} \Delta t^{\prime}
$$

equation (4) has general solution as follows,

$$
\begin{gathered}
{[A A]=\frac{B \exp \left(-B K_{A A^{\prime}} t^{\prime}\right)}{r\left[H^{+}\right]_{P A G}+\exp \left(-B K_{A A} t^{\prime}\right)}} \\
\because B \equiv r\left(\left[H^{+}\right]_{P A G}+1\right)
\end{gathered}
$$

By substituting this to equation(2), we obtain

$$
\begin{aligned}
& {\left[H^{+}\right]_{\text {TOTAL }}=r[H+]_{P A G}+\left[H^{+}\right]_{A A}} \\
& =\frac{r\left[H^{+}\right]_{P A G}\left(r\left[H^{+}\right]_{P A G}+1\right)}{r\left[H^{+}\right]_{P A G}+\exp \left\{-\left(r\left[H^{+}\right]_{P A G}+1\right) K_{A A} t^{\prime}\right\}}
\end{aligned}
$$

Figure 13 and 14 show the calculated total acid amount as a function of $\mathrm{H}_{\text {PAG. }}^{+}$The total acid amount is proportional to the amount of $\mathrm{H}^{+}$PAG. This suggests that the acid amplification reaction improves sensitivity but does not improve contrast.

Figure 15 shows the total acid amount as a function of PEB time. The amount of acid is exponentially increased with the increase in PEB time.

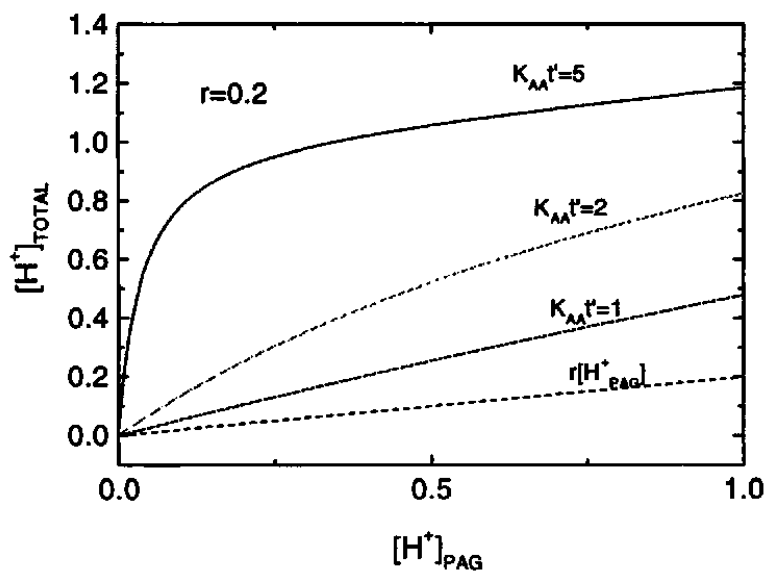

Fig. 13 Simulated total acid amount as a function of photo-induced acid. $\quad(r=0.2)$ 


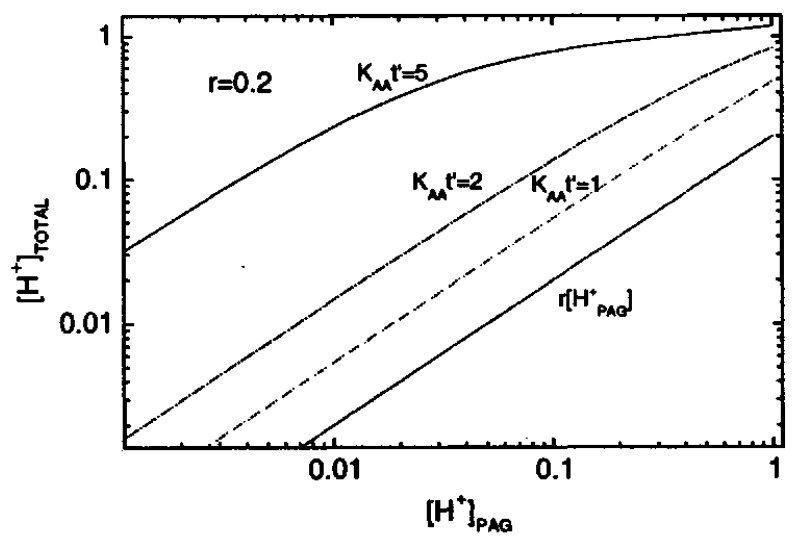

Fig. 14 Logarithmic expression of simulated total acid amount as a function of photo-induced acid. $\quad(r=0.2)$

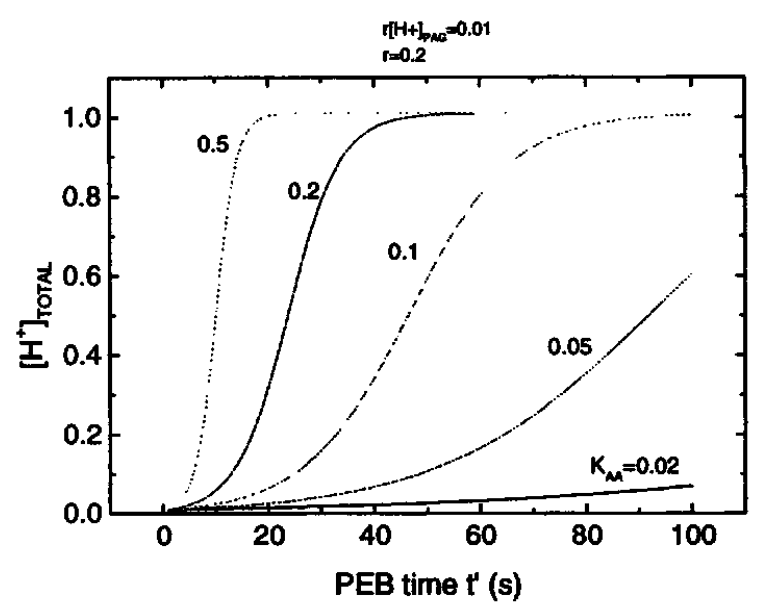

Fig. 15 Simulated acid amount as a function of PEB time. $\left(\mathrm{r}=0.2,\left[\mathrm{H}^{+}\right]_{\mathrm{PAG}}=0.05\right)$

(ii) when $m \neq 1$.

The reaction order of acid was reported as 1.4 in the deprotection reaction.[13-14] The reaction order of acid amplification is thought to be greater than 1. However, solving equation (4) is difficult when $m \neq 1$. Therefore, we analytically solved equation (4) using a computer. The results are indicated in Figure 16 and 17. The calculations were carried out changing $\mathrm{m}$ from 1 to 2. In the case of $m=2$, the slope improved two times. This increase in slope may consequently improve resist contrast.

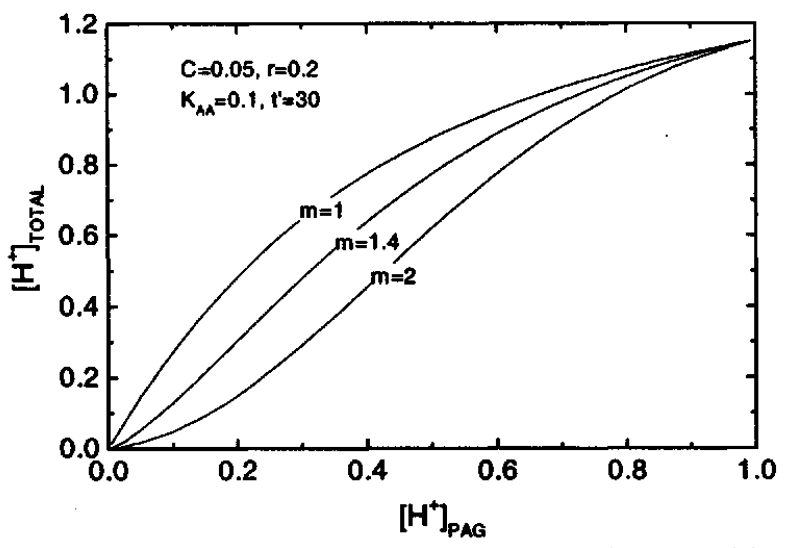

Fig. 16 Reaction order dependence of an acid amplification reaction obtained from analytical calculation.

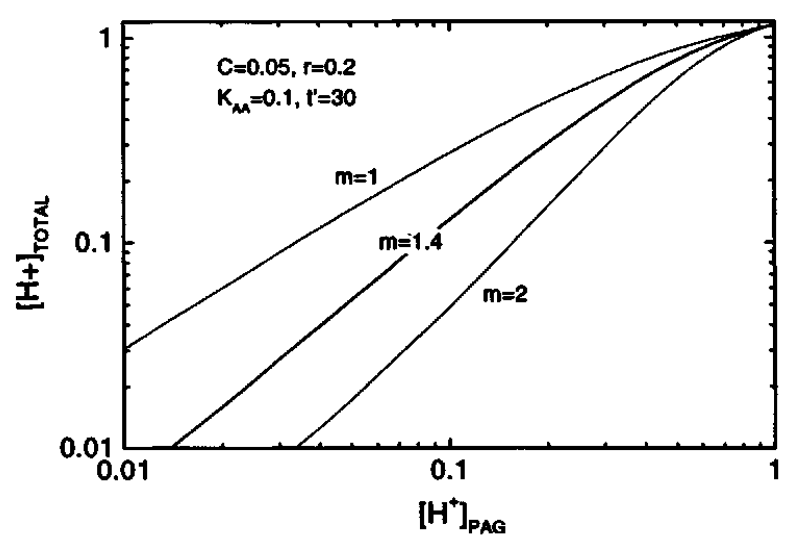

Fig. 17 Logarithmic expression of the reaction order dependence of the acid amplification reaction.

\subsection{Process window analysis}

In this section, we will analyze process window dependence on the reaction order using the lithography simulator, PROLITH/2. In these analyses, we used as reference parameters the development parameters which were fitted to the measured dissolution rate for an ArF chemically amplified resist.[14] Regrading $n$ values, which correspond to the slope of the dissolution rate curve, we used $n^{*} m$ values as a parameter $n$ in the case of $m \neq 1$. The simulation parameters are listed in Table 2. The process window criteria were $\Delta \mathrm{cd}$ within $\pm 10 \%$ and side-wall angle larger than $83^{\circ}$. The exposure lens was $N A=0.55$ and the analyzed patterning linewidth was $0.2 \mu \mathrm{m}$. 
Table 2. Simulation parameters used in process window analysis.

\begin{tabular}{|c|c|c|}
\hline \multirow{4}{*}{ optical } & parameters & values \\
\cline { 2 - 3 } & $\lambda$ & $193 \mathrm{~nm}$ \\
\cline { 2 - 3 } & $\mathrm{N} \mathrm{A} / \sigma$ & $0.55 / 0.5$ \\
\hline \multirow{4}{*}{$\begin{array}{c}\text { dissolution } \\
\text { rate }\end{array}$} & Linewidth & $0.2 \mu \mathrm{m}$ \\
\cline { 2 - 3 } & $\mathrm{R}_{\max }$ & $112 \mathrm{~nm} / \mathrm{s}$ \\
\cline { 2 - 3 } & $\mathrm{R}_{\min }$ & $0.1 \mathrm{~nm} / \mathrm{s}$ \\
\hline \multirow{4}{*}{ resist } & $\mathrm{M}_{\mathrm{th}}$ & 0.46 \\
\cline { 2 - 3 } & $\mathrm{n}$ & $4.8 / 9.6$ \\
\cline { 2 - 3 } & $\mathrm{A}$ & $0 / \mu \mathrm{m}$ \\
\cline { 2 - 3 } & $\mathrm{B}$ & $0.51 / \mu \mathrm{m}$ \\
\cline { 2 - 3 } & $\mathrm{C}$ & $0.05 \mathrm{~cm} / \mathrm{mJ}$ \\
\hline \multirow{4}{*}{$\begin{array}{c}\text { process } \\
\text { window }\end{array}$} & Thickness & $0.51 \mu \mathrm{m}$ \\
\cline { 2 - 3 } & $\Delta \mathrm{cd}$ & $>10 \%$ \\
\hline
\end{tabular}

Figure 18 shows the simulated process window. When the reaction order is increased to 2 from 1 , the process window area increases by 2 . The reaction order in the acid amplification reaction was estimated as 1.4. The process window can be increased 1.5 times when we use an acid amplification mechanism.

Although an acid amplification mechanism will improve the process window, this process window increase is not large enough for the manufacture devices. Further improvement will be required for $193 \mathrm{~nm}$ lithography.

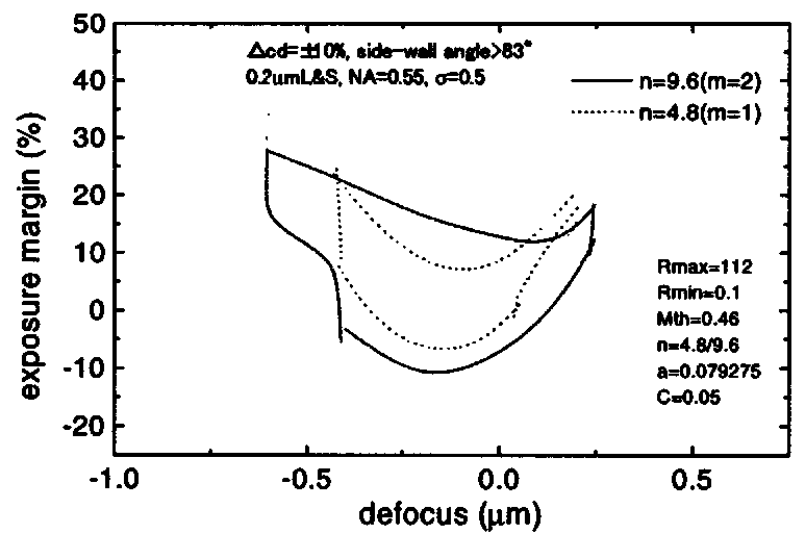

Fig. 18 Simulated process window calculated from PROLITH/2 for different reaction orders.

\section{CONCLUSION}

Introducing an acid amplification mechanism into a chemically amplified resist at $193 \mathrm{~nm}$ improves sensitivity and resolution. To maximize these advantages, a more transparent acid amplifier is required. The simulation model of an acid amplification reaction was proposed. The simulation analysis clarified that the use of this reaction will improve the process window.

\section{ACKNOWLEDGMENTS}

This work was supported by NEDO.

\section{APPENDIX}

equation (4) is written as follows,

$$
\frac{\Delta[A A]}{B[A A]-[A A]^{2}}=-\mathrm{K}_{\mathrm{AA}} \Delta \mathrm{t}^{\prime}
$$

eq. (4)' is written as follows,

$$
\left(\frac{1}{[A A]}+\frac{1}{B-[A A]}\right) \Delta[A A]=-B \cdot K_{A A} \cdot \Delta t^{\prime}
$$

By integrating, we get

$$
\log [A A]-\log (B-[A A])=-B K_{A A} t^{\prime}+C
$$

When $t^{\prime}=0,[A A]=1$, then

$$
\begin{aligned}
& C=-\log (B-1) \\
& \therefore \log \frac{[A A]}{B-[A A]}=-B \cdot K_{A A} \cdot t^{\prime}-\log (B-1) \\
& \log \frac{\{(B-1)[A A]\}}{B-[A A]}=-B \cdot K_{A A} \cdot t^{\prime} \\
& \therefore \frac{(B-1)[A A]}{B-[A A]}=\exp \left(-B \cdot K_{A A} \cdot t^{\prime}\right) \\
& \therefore[A A]=\frac{B \exp \left(-B K_{A A} t^{\prime}\right)}{(B-1)+\exp \left(-B K_{A A} t^{\prime}\right)}
\end{aligned}
$$

substituting eq. (5) t o eq. (2),

$$
\left[H^{+}\right]_{T O T A L}=r[H+]_{P A G}+\left[H^{+}\right]_{A A}
$$




$$
\begin{aligned}
& =r\left[H^{+}\right]_{P A G}+1-\frac{B \exp \left(-B K_{A A} t^{\prime}\right)}{r\left[H^{+}\right]_{P A G}+\exp \left(-B K_{A A} t^{\prime}\right)} \\
& =\frac{r\left[H^{+}\right]_{P A G}\left(r\left[H^{+}\right]_{P A G}+1\right)}{r\left[H^{+}\right]_{P A G}+\exp \left\{-\left(r\left[H^{+}\right]_{P A G}+1\right) K_{A A} t^{\prime}\right\}}
\end{aligned}
$$

\section{REFERENCES}

1. S. Takechi, Y. Kaimoto, K. Nozaki, and N. Abe , J. Photopolym. Sci. Technol., 5, 439 (1992).

2. K. Nakano, K. Maeda, S. Iwasa, T. Ohfuji, and E. Hasegawa, Proc. SPIE 2438, 433 (1995).

3. R. D. Allen, G.M. Wallraff, R.A. DiPietro, D.C. Hofer, and R.R. Kunz,, Proc. SPIE 2438, 474 (1995).

4. K. Maeda, K. Nakano, T. Ohfuji, and Etsuo Hasegawa, Proc. SPIE 2724, 377 (1996).

5. Naomi Shisa, Tohru Ushiroguchi, Kohji Asakawa, and Makoto Nakase, J. Photopolymer Sci. Technol. Vol. 9, No. 3, 457 (1996).
6. K. Ichimura, K. Arimitsu and K. Kazuaki, Chem. Lett., 551-552 (1995).

7. K. Arimitsu, K. Kudo, H. Ohmori, and K. Ichimura, J. Photopolym. Sci. Technol., 8, 4344.

8. K. Kudo, K. Arimitsu, H. Ohmori, and K. Ichimura, J. Photopolym. Sci. Technol., 8, 45-46 (1995).

9. K. Kudo, K. Arimitsu, and K. Ichimura, Mol. Cryst. Liq. Cryst., 280, 307-312 (1996).

10. H. Ohmori, K. Arimitsu, K. Kudo, Y. Hayashi and K Ichimura, J. Photopolym. Sci. Technol., 9, 25-28 (1996)

11. K. Arimitsu, K. Kudo, Y. Hayashi, and K. Ichimura, J. Photopolym. Sci. Technol., 9, 2930 (1996)

12. Kunihiro Ichimura, Koji Arimitsu, and Kazuaki Kudo,, Chemistry Letters 551 (1995).

13. Takeshi Ohfuji, Proc. SPIE, Vol. 1925, 213, (1993).

14. T. Ohfuji, K. Nakano, K. Maeda, and E. Hasegawa, J. V. Sci. Technol. B, Vol. 13, No. 6, 3022 (1995). 